\title{
Structure and Protein-Protein Interactions of Human UDP-Glucuronosyltransferases
}

\author{
Ryoichi Fujiwara ${ }^{*}$, Tsuyoshi Yokoi ${ }^{2}$ and Miki Nakajima ${ }^{3}$ \\ ${ }^{1}$ Department of Pharmaceutics, School of Pharmacy, Kitasato University, Tokyo, Japan, ${ }^{2}$ Department of Drug Safety \\ Sciences, Division of Clinical Pharmacology, Nagoya University Graduate School of Medicine, Nagoya, Japan, ${ }^{3}$ Drug \\ Metabolism and Toxicology, Faculty of Pharmaceutical Sciences, Kanazawa University, Kanazawa, Japan
}

OPEN ACCESS

Edited by:

Yuji Ishii,

Kyushu University, Japan

Reviewed by:

Karl Walter Bock

University of Tübingen, Germany

Ben Lewis,

Flinders University, Australia

${ }^{*}$ Correspondence:

Ryoichi Fujiwara

fujiwarar@pharm.kitasato-u.ac.jp

Specialty section:

This article was submitted to

Pharmacogenetics and Pharmacogenomics,

a section of the journal

Frontiers in Pharmacology

Received: 15 August 2016 Accepted: 05 October 2016 Published: 24 October 2016

Citation:

Fujiwara $R$, Yokoi $T$ and Nakajima $M$ (2016) Structure and Protein-Protein Interactions of Human

UDP-Glucuronosyltransferases.

Front. Pharmacol. 7:388

doi: 10.3389/fphar.2016.00388
Mammalian UDP-glucuronosyltransferases (UGTs) catalyze the transfer of glucuronic acid from UDP-glucuronic acid to various xenobiotics and endobiotics. Since UGTs comprise rate-limiting enzymes for metabolism of various compounds, coadministration of UGT-inhibiting drugs and genetic deficiency of UGT genes can cause an increased blood concentration of these compounds. During the last few decades, extensive efforts have been made to advance the understanding of gene structure, function, substrate specificity, and inhibition/induction properties of UGTs. However, molecular mechanisms and physiological importance of the oligomerization and proteinprotein interactions of UGTs are still largely unknown. While three-dimensional structures of human UGTs can be useful to reveal the details of oligomerization and proteinprotein interactions of UGTs, little is known about the protein structures of human UGTs due to the difficulty in solving crystal structures of membrane-bound proteins. Meanwhile, soluble forms of plant and bacterial UGTs as well as a partial domain of human UGT2B7 have been crystallized and enabled us to predict three-dimensional structures of human UGTs using a homology-modeling technique. The homologymodeled structures of human UGTs do not only provide the detailed information about substrate binding or substrate specificity in human UGTs, but also contribute with unique knowledge on oligomerization and protein-protein interactions of UGTs. Furthermore, various in vitro approaches indicate that UGT-mediated glucuronidation is involved in cell death, apoptosis, and oxidative stress as well. In the present review article, recent understandings of UGT protein structures as well as physiological importance of the oligomerization and protein-protein interactions of human UGTs are discussed.

Keywords: UDP-glucuronosyltransferase (UGT), protein-protein interactions, glucuronidation, glucuronides, drug-metabolizing enzymes

\section{INTRODUCTION}

Humans are exposed on a daily basis to xenobiotics that may potentially be toxic or pharmacologically active. Xenobiotics are often hydrophobic and therefore may accumulate in the body. To facilitate the excretion of xenobiotics, detoxifying enzymes metabolize them mostly in the liver to increase their hydrophilicity. Since such xenobiotic-metabolizing enzymes play an important role in the metabolism of clinically used drugs, they are also called drugmetabolizing enzymes. Phase I drug-metabolizing enzymes, such as cytochrome P450s (CYPs) and 
esterases, catalyze oxidation, reduction, and hydrolysis of xenobiotics (Satoh and Hosokawa, 1998; Nebert and Russell, 2002). The formed metabolites, as well as parental compounds, are further metabolized by phase II drug-metabolizing enzymes, such as UDP-glucuronosyltransferases (UGTs), sulfotransferases, and glutathione $S$-transferases (Jancova et al., 2010; Miners et al., 2010). Among these, UGTs have been reported with the highest contribution to drug metabolism (Williams et al., 2004).

UDP-glucuronosyltransferases-mediated glucuronidation can be a rate-limiting step in the clearance of endogenous and exogenous substances. Therefore, inhibition of UGTs by coadministered drugs or genetic deficiency in the UGT gene can increase blood concentrations of their substrates in vivo, whereas induction of UGT genes would result in a decrease of blood concentrations of their substrates (Lankisch et al., 2009; Hirashima et al., 2016). Three-dimensional crystal structures are useful to facilitate the understanding of protein structures that determine substrate- and/or inhibitor-binding. Due to the difficulty in obtaining the crystal structure of membrane proteins, entire three-dimensional structures of human UGTs have not been determined except for a partial domain of human UGT (Miley et al., 2007). On the other hand, entire crystal structures of soluble forms of plant and bacterial UGTs have previously been reported (Mulichak et al., 2003; Shi et al., 2014). These solved structures were used as templates of homology modeling of human UGTs (Fujiwara et al., 2009a). Although amino acid similarities are not high between mammalian and plant/bacterial UGTs, the modeled human UGT structures are comparable to plant and bacterial UGTs, suggesting that the structures of plant/bacterial UGTs may aid in the structural clarification of human UGTs.

UDP-glucuronosyltransferases enzymes comprise a superfamily. One of the most unique and important properties of UGTs is that they form homo- and hetero-oligomers such as dimers, trimers, and tetramers (Finel and Kurkela, 2008). Tukey and Tephly (1981) were the first to report that rat UGTs functioned in an oligomeric form. Subsequently, various in vitro techniques such as cross-linking and fluorescence resonance energy transfer (FRET) imaging demonstrated the oligomerization of UGT proteins (Ikushiro et al., 1997; Operaña and Tukey, 2007). Interestingly, accumulating evidence indicates that UGT-UGT interactions affect their enzymatic activities (Ishii et al., 2001; Fujiwara et al., 2007a,b). Analyses using the homology-modeled UGT structures further revealed the region responsible for the oligomerization of UGTs (Lewis et al., 2011). Moreover, specific antibodies against UGTs immunoprecipitated not only UGTs but also CYPs in human liver microsomes, indicating that UGTs appeared to interact with other microsomal proteins (Fujiwara and Itoh, 2014). Indeed, recently developed techniques such as mass spectrometry analysis of immunoprecipitates revealed that UGTs may interact with a variety of microsomal proteins including epoxide hydrolase 1, carboxylesterase 1, alcohol dehydrogenases, and glutathione $S$-transferases (Fujiwara and Itoh, 2014).

In this review article, recent advances in the knowledge on the three-dimensional structure, protein interactions of human UGTs, and physiological roles of UGTs are introduced along with early and recent analytical tools that demonstrate the presence of UGT oligomers.

\section{UDP-GLUCURONOSYLTRANSFERASE (UGT)}

\section{Human UGT Families and Their Function}

UDP-Glucuronosyltransferase (UGT, EC 2.4.1.17), which belongs to a large glycosyltransferase (GT) 1 family of GTs (EC 2.4.1.-; GT), is a family of membrane-bound proteins that catalyze a transfer of glucuronic acid from UDP-glucuronic acid to various endogenous and exogenous substances (Figure 1) (Mackenzie et al., 2005). UGTs are specifically expressed in the ER and most the UGTs are localized in the luminal side of the ER-membrane, which is rich in UDP-glucuronic acid. In humans, the UGT gene superfamily contains UGT1 and UGT2.

The single human UGT1 gene, located on chromosome 2q37.1, contains multiple exon 1 s and common exons 2-5, spanning approximately $200 \mathrm{kbp}$. Individual UGT1 isoforms, UGT1A1, UGT1A3, UGT1A4, UGT1A5, UGT1A6, UGT1A7, UGT1A8, UGT1A9, and UGT1A10, are generated by exon sharing of the UGT1 gene (Figure 2A). Importantly, Dr. Girard et al. (2007) discovered that there are two types of exon 5, exons $5 \mathrm{a}$ and $5 \mathrm{~b}$, which encodes a shorter amino acid sequence. Compared to $50-55 \mathrm{kDa}$ proteins encoded by exons $1-4$ and $5 \mathrm{a}$ (UGT1A_i1), which is a main variant, the proteins encoded by exons $1-4$ and 5b (UGT1A_i2) are smaller (45 kDa) and generally exhibit lower enzymatic activities.

Human UGT2 genes, including UGT2A and UGT2B, are located on chromosome 4q13.2. UGT2A1 and UGT2A2 are generated by exon sharing of unique exon $1 \mathrm{~s}$ and common exons 2-6 of the UGT2A gene in the same manner as UGT1A proteins, whereas a single gene encodes UGT2A3. UGT2B family proteins, UGT2B4, UGT2B7, UGT2B10, UGT2B11, UGT2B15, UGT2B17, and UGT2B28, are encoded by each unique gene in a cluster (Figure 2B). Transcriptional diversity has been reported in the UGT2B7 locus. Original six exons as well as extra three exon 1 s and two exon 6 s of the UGT2B7 gene can produce up to 22 transcript variants which encode 7 types of UGT2B7 proteins (UGT2B7_i1 to_i7) (Ménard et al., 2011). Similar to UGT1A_i1, UGT2B7_i1 exhibits the highest enzyme activity compared to UGT2B7_i2 to _i7 proteins. Recently conducted targeted RNA next-generation sequencing revealed that transcriptional diversity, such as new internal exons and exon skipping, could be observed in other UGT2B genes (Tourancheau et al., 2016). The expression and enzyme activities of such alternative UGT2Bs need to be determined in the future.

\section{Tissue Distribution of UGTs}

In humans, all of 9 UGT1 and 10 UGT2 isoforms are expressed in a tissue-specific manner. In the liver, which is the most important tissue in metabolism of xenobiotics, UGT1A1, UGT1A3, UGT1A4, UGT1A6, UGT1A9, UGT2B4, UGT2B7, UGT2B10, UGT2B15, and UGT2B17 are expressed (Nakamura et al., 2008; Izukawa et al., 2009). UGT1A8 and UGT1A10 are mainly expressed in the small intestine, colon, and bladder. 


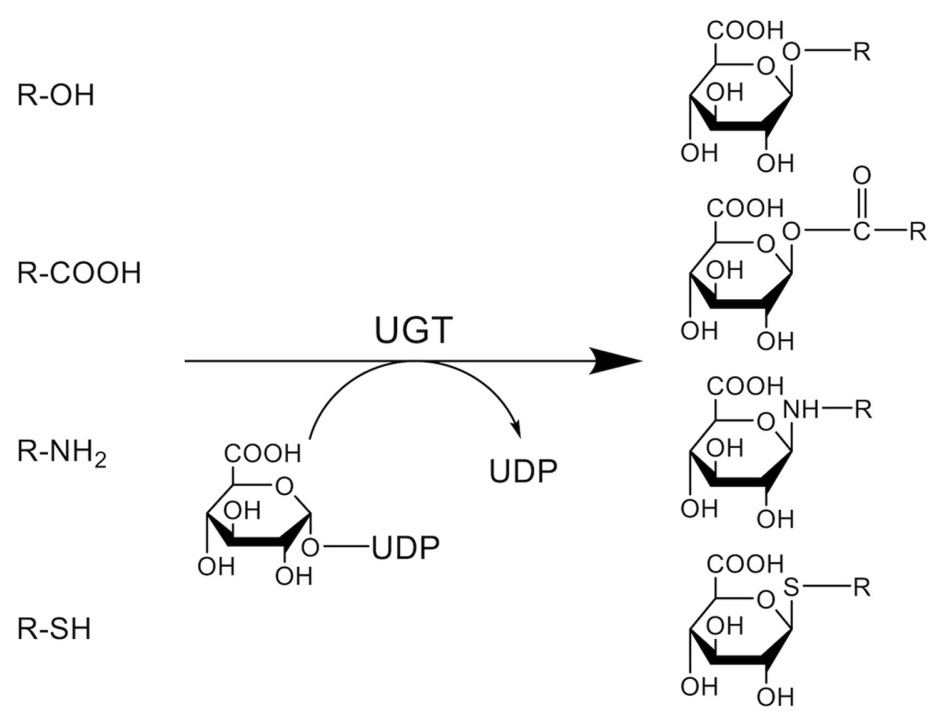

FIGURE 1 | Conjugation reaction catalyzed by UDP-glucuronosyltransferases (UGTs). UGTs catalyze the transfer of glucuronic acid from UDP-glucuronic acid to an oxygen, nitrogen, or sulfur atom of their substrates. ( $R=$ substrate).

A

\section{Human UGT1}

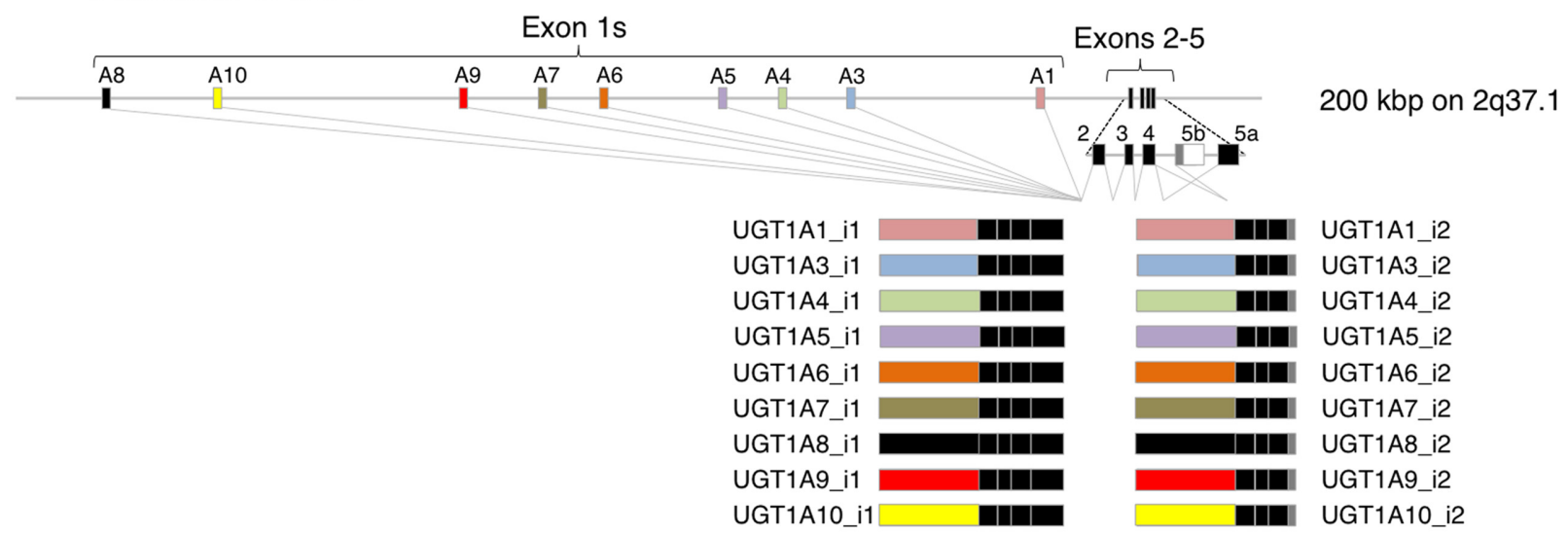

B Human UGT2

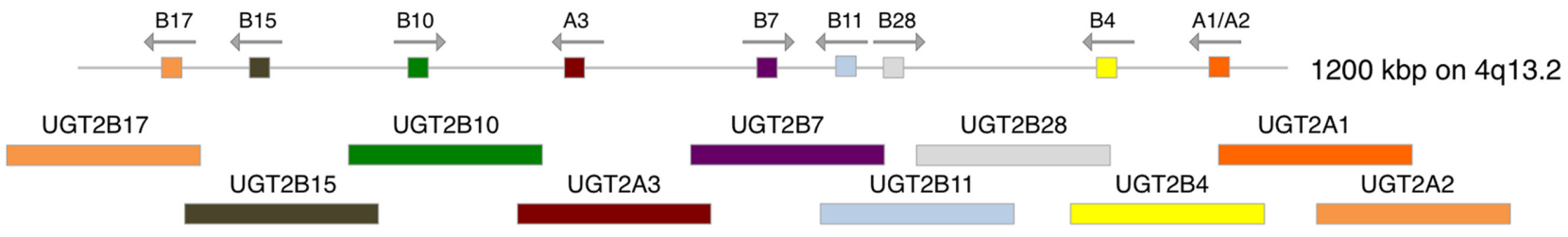

FIGURE 2 | Gene structures of human UGT1 and UGT2. (A) Human UGT1 gene contains multiple exon 1s and common exons 2-5, and each UGT1 isoform are generated by exon sharing of the gene. Exon 5a produces UGT1A_i1 proteins, while exon 5b produced smaller UGT1A_i2 proteins. (B) UGT2A1 and UGT2A2 are generated by exon sharing of unique exon 1s and common exons 2-6 of the UGT2A gene in the same manner as UGT1A proteins. UGT2A3 and UGT2B family proteins are encoded by each unique gene in a cluster. 
UGT1A7 has been characterized as an isoform that is specifically expressed in the stomach (Strassburg et al., 1997). In the kidneys, UGT1A9 and UGT2B7 are highly and other UGTs such as UGT1A4, UGT1A6, and UGT2B11 are moderately expressed. The expression of UGT2B28 is limited to the bladder, where various UGT1 and UGT2 members are also expressed. UGT2A1 and UGT2A2 are expressed in nasal tissue, whereas UGT2A3 is expressed mainly in liver and small intestine, and slightly in lung and nasal tissues (Sneitz et al., 2009). Since UGT2A family isoforms glucuronidate endogenous substances rather than drugs, it has been believed that they have certain physiological role in those organs, although more investigation is required.

\section{Substrate Specificity of UGTs}

UDP-glucuronosyltransferases catalyze the transfer of glucuronic acid from UDP-glucuronic acid to an oxygen, nitrogen, or sulfur atom in their substrates (Figure 1). UGT1A1 glucuronidates relatively bulky molecules such as bilirubin, SN-38, and etoposide, as well as planar or smaller molecules such as estradiol, 1-naphthol, and 4-methylumbelliferone (Bosma et al., 1994; Watanabe et al., 2003; Mano et al., 2004). While these smaller compounds can be glucuronidated by several other UGT1 and UGT2 family proteins, bilirubin is solely glucuronidated by UGT1A1 (Bosma et al., 1994). UGT1A4 has been recognized as one of the UGT isoforms that can glucuronidate tertiary amines (e.g., nicotine, imipramine, trifluoperazine, and lamotrigine) (Kuehl and Murphy, 2003; Smith et al., 2003; Rowland et al., 2006). A recent study demonstrated that clearances of nicotine, amitriptyline, imipramine, and diphenhydramine by UGT2B10mediated $N$-glucuronidation were significantly higher than those by UGT1A3 and UGT1A4, indicating that UGT2B10 plays an important role in $\mathrm{N}$-glucuronidation of certain aminecontaining compounds (Kato et al., 2013). As UGT1A6 was originally characterized as a phenol-glucuronidating enzyme, it mainly glucuronidates small phenolic substances such as 4nitrophenol, 1-naphthol, and 4-methylumbelliferone (Hanioka et al., 2001). 5-Hydroxytriptamine, also called serotonin, has been recognized as a specific substrate of UGT1A6 (Krishnaswamy et al., 2003). UGT1A9 metabolizes a wide variety of substances such as mycophenolic acid, scopoletin, and entacapone (Kurkela et al., 2003; Bernard and Guillemette, 2004). Propofol has been used as a selective substrate of UGT1A9 in the livers, although it can also be glucuronidated by UGT1A7, UGT1A8, and UGT1A10 in the gastrointestine (Court, 2005). UGT2B isoforms are especially important in the glucuronidation of endogenous compounds such as androsterone, testosterone, and dihydrotestosterone. Zidovudine and morphine are specifically metabolized by UGT2B7 (Barbier et al., 2000). It has been shown that UGT2B15 is the major enzyme responsible for sipoglitazar glucuronidation in humans, while multiple UGT1A and UGT2B members slightly glucuronidate sipoglitazar (Nishihara et al., 2013). UGT2B17, which has more than 95\% homology with UGT2B15, can glucuronidate a wide variety of exogenous and endogenous compounds, including coumarins, anthraquinones, flavonoids, and androgens (Turgeon et al., 2003). Therefore, each UGT isoform exhibits broad but distinct substrate specificities.

\section{Significance of Extrahepatic UGTs}

Because bilirubin is solely glucuronidated by UGT1A1, genetic deficiency in the UGT1A1 gene can result in an onset of severe hyperbilirubinemia ( $>20 \mathrm{mg} / \mathrm{dL}$ serum bilirubin) in humans (Beutler et al., 1998). Knockout of Ugt1a1 in mice causes very severe hyperbilirubinemia ( $>15 \mathrm{mg} / \mathrm{dL}$ serum bilirubin), which is lethal within 11 days of birth due to the development of kernicterus (Nguyen et al., 2008). Since UGT1A1 is highly expressed in the liver, it was previously commonly believed that hepatic UGT1A1 mainly contribute to the bilirubin glucuronidation. However, a recent study demonstrated that liver-specific knockout of the Ugt1 gene, including Ugt1a1, resulted in a mild increase of serum bilirubin $(2 \mathrm{mg} / \mathrm{dL}$ serum bilirubin; Chen et al., 2013). Furthermore, increased expressions of intestinal UGT1A1 lead to decreased serum bilirubin levels (from 12 to $2 \mathrm{mg} / \mathrm{dL}$ ) in 14-day-old humanized UGT1 mice, indicating that intestinal UGT1A1 also plays an important role in bilirubin metabolism (Fujiwara et al., 2010b, 2012). UGT1A1 expressed in the skin and brain might also be responsible for bilirubin metabolism in neonates although to a lesser extent (Sumida et al., 2013; Kutsuno et al., 2015). In addition to UGT1A1, substantial expression of UGT1A8 and UGT1A10 mRNA are also observed in the small intestine (Nakamura et al., 2008). Since recombinant UGT1A1, UGT1A8, and UGT1A10 glucuronidate raloxifene in vitro, these enzymes might be responsible for the extremely poor oral bioavailability of raloxifene (Mizuma, 2009). However, it should be noted that the UGT1A8 protein was barely detected in human small intestine in a targeted peptide-based quantification study (Sato et al., 2014). Therefore, the role of UGT1A8 in intestinal glucuronidation in vivo needs to be carefully investigated in the future. These data support a concept that in addition to hepatic UGTs, extrahepatic UGTs also play a dominant role in glucuronidation of endogenous and exogenous compounds (Fujiwara et al., 2015).

\section{THREE-DIMENSIONAL STRUCTURE OF HUMAN UGTS}

\section{Structure of Glycosyltransferase 1 Family Protein}

Due to difficulties in crystallizing membrane-bound protein, X-ray crystal structures of membrane-bound human UGTs have not been determined. As mentioned above, human UGTs belong to a large glycosyltransferase (GT) 1 family. Because plant and bacterial GT1 family proteins are soluble forms, several X-ray crystal structures of plant and bacterial GTs have successfully been determined. In 2003, a 2.8crystal structure of TDP-epi-vancosaminyltransferase (GtfA), which is one of the GT1 family proteins that transfer 4-epivancosamine from TDP-epi-vancosamine to its substrate, in Amycolatopsis orientalis was solved (Mulichak et al., 2003). The crystal structure (PDB ID: 1PN3) revealed that GtfA adopts a GT-B fold that consists of two separate Rossmann domains with a connecting linker and a catalytic cleft. In addition, other GT1 family proteins such as plant UDP-glucose 
flavanoid 3-O glucosyltransferase (2C1X) and multifunctional triterpene/flavonoid glycosyltransferase UGT71G1 (2ACV) also have the GT-B fold (Shao et al., 2005; Offen et al., 2006). These findings lead us to hypothesize that human UGTs would also be GT-B fold enzymes.

\section{Predicted Structure of Human UGTs}

Human UGT1 and UGT2 family members consist of approximately 530 amino acids. One of the unique properties of UGTs is that they sometimes recognize overlapping but specific substrates, while they commonly recognize a co-substrate UDPglucuronic acid (Mackenzie et al., 2005). Because UGT1 family proteins are generated by exon sharing of the single UGT1 gene (Figure 2A), their C-terminal amino acid sequences encoded by the common exons $2-5$ are identical. Although UGT2 family proteins are encoded by their individual genes (Figure 2B), the C-terminal amino acid sequences exhibit extremely high amino acid similarity. In contrast, the $\mathrm{N}$-terminal amino acid sequences of UGT1 and UGT2 family members exhibit relatively lower amino acid similarity. For example, the sequence homology is 24-49\% between N-terminal regions of UGT1 family enzymes (Mackenzie et al., 1997). Point mutation analyses demonstrated that mutations in the $\mathrm{N}$ - and C-terminal halves dramatically decreased the affinities toward substrates and UDP-glucuronic acid, respectively (Xiong et al., 2006; Patana et al., 2007; Fujiwara et al., 2009b; Kerdpin et al., 2009). These mutagenesis studies support an assumption that human UGTs have two domains, the highly conserved C-terminal halves responsible for the UDP-glucuronic acid binding and the unique $\mathrm{N}$-terminal halves responsible for the substrate binding. A 1.8 - $\AA$ resolution apo crystal structure of the C-terminal half of human UGT2B7 $(2 \mathrm{O} 6 \mathrm{~L})$, which is a solely available X-ray crystal structure of human UGTs, confirmed that the C-terminal domain contained a preserved nucleotide-sugar binding site (Miley et al., 2007).

\section{Homology-Modeled Structure of Human UGTs}

Three-dimensional structures of unsolved proteins can be modeled by homology-modeling. Locuson and Tracy (2007) conducted homology modeling of human UGT1A1 using the crystallized structure of plant UGT71G1 (2ACV) as a template. The length of the amino acid sequence of human UGT1A1 (533 amino acids) is relatively longer than that of plant UGT71G1 (463 amino acids). The amino acid similarity between UGT1A1 and UGT71G1 is $34 \%$, but it was sufficient to obtain a reliable homology-model. The overall three-dimensional structure of UGT1A1 showed two Rossmann fold-like domains (Locuson and Tracy, 2007). Banerjee et al. (2008) modeled a three-dimensional structure of human UGT1A10 using UDP-galactose 4-epimerase (1XEL) from Escherichia coli as a template structure (Banerjee et al., 2008). The modeled structures of substrate- and UDP sugar-binding pockets were overlapped well with those of the template structure. The structural analysis indicated that lysine residues at 314 and 404 (K314 and K404) would play a critical role in the UDP-glucuronic acid binding of UGT1A10. They confirmed, by in vitro mutagenesis analysis, the importance of
K314 and K404 in the UDP-glucuronic acid binding. Therefore, the homology-modeled structures of human UGTs are relatively reliable, even though the amino acid similarities are not high between human and plant/bacteria UGTs. Similar homologymodeling approaches have been carried out by many research groups to simulate the three dimensional structures of human UGTs (Table 1). Structural similarity of C-terminal domains was very high between the modeled structures and the crystallized structure of the C-terminal half of human UGT2B7 (2O6L), supporting the reliability of the homology-modeling technique (Figure 3).

Among the 19 functional human UGT proteins, UGT1A9 exhibits several unique properties. In 2007, we demonstrated that UGT1A9 was uniquely stable against heat treatment, while the other human UGTs lost their enzymatic activities when incubated at higher temperature (Fujiwara et al., 2007b). Importantly, 13 amino acid residues were found to be specific to UGT1A9 among 9 UGT1A isoforms. To examine the role of these residues in the thermal stability of UGT1A9, we conducted molecular dynamics simulation of homology-modeled structures of UGT1A9 as well as UGT1A8 as a reference at higher and lower temperatures. The in silico simulation revealed that the UGT1A9-specific residues were collectively involved in the thermal stability of UGT1A9 (Fujiwara et al., 2009b). In vitro mutagenesis analysis confirmed that the UGT1A9-specific residues, Arg42, Lys91, Ala92, Tyr106, Gly111, Tyr113, Asp115, Asn152, Leu173, Leu219, His221, Arg222, and Glu241, contributed to protein stability. Since the results of in silico and in vitro analyses were consistent, it is considered that the homology-modeled structure of human UGT1A9 (Figure 3) was relatively reliable.

\section{DIMERIZATION AND OLIGOMERIZATION OF UGTs}

The first evidence to demonstrate the oligomerization of mammalian UGTs was reported by Tukey and Tephly (1981). Shortly after the publication, Matern et al. (1982) demonstrated oligomeric UGTs in . Subsequently, a number of research groups showed that mammalian UGTs including human UGTs formed homo- and hetero-oligomers such as dimers, trimers, and tetramers. In this section, earlier and recent analytical tools used to show the oligomeric UGTs are summarized.

\section{Gel Permeation Chromatography}

Tukey and Tephly (1981) purified two different UGT isoforms, which mediate estrone and $p$-nitrophenol glucuronidations, respectively, from rabbit liver microsomes by DEAE-cellulose chromatography and affinity chromatography on UDPhexanolamine Sepharose-4B. Both enzymes exhibited molecular weights of $57 \mathrm{kDa}$ in the SDS-PAGE analysis. Interestingly, a gel filtration study of the purified UGT isoforms by an Ultragel AcA 34 column revealed that both UGTs had apparent molecular weights of $230 \mathrm{kDa}$ (Tukey and Tephly, 1981), which is approximately 4 times larger than the size of monomeric UGTs. This was the first report demonstrating that mammalian UGTs could be present as tetramers. 
TABLE 1 | Homology modeled human UDP-glucuronosyltransferases (UGTs) and their template structures.

\begin{tabular}{|c|c|c|c|}
\hline Modeled UGT & Template & Template PDB ID & Reference \\
\hline UGT1A1 & Medicago truncatula triterpene UDP-glucosyl transferase (UGT71G1) & 2ACV & Locuson and Tracy, 2007 \\
\hline UGT1A1 & Medicago truncatula triterpene UDP-glucosyl transferase (UGT71G1) & 2ACV & Li and Wu, 2007 \\
\hline \multirow[t]{4}{*}{ UGT1A1 } & Arabidopsis thaliana hydroquinone glucosyltransferase (UGT72B1) & 2VCE & Laakkonen and Finel, 2010 \\
\hline & Amycolatopsis orientalis UDP-glycosyltransferase (GtfB) & $1 \| R$ & \\
\hline & Streptomyces antibioticus oleandomycin glycosyltransferase & 2IYA & \\
\hline & Homo sapiens UGT2B7 (C-terminal domain) & $206 \mathrm{~L}$ & \\
\hline \multirow[t]{3}{*}{ UGT1A1 } & Arabidopsis thaliana hydroquinone glucosyltransferase (UGT72B1) & 2VCE & Song et al., 2015 \\
\hline & Streptomyces antibioticus oleandomycin glycosyltransferase & 2IYA & \\
\hline & Vitis vinifera UDP-glucose flavonoid 3-o-glycosyltransferase (VvGTI) & $2 \mathrm{C} 1 \mathrm{X}$ & \\
\hline \multirow[t]{3}{*}{ UGT1A3 } & Medicago truncatula multifunctional (iso)flavonoid glycosyltransferase (UGT85H2) & 2PQ6 & Song et al., 2015 \\
\hline & Vitis vinifera UDP-glucose flavonoid 3-o-glycosyltransferase (VvGTI) & $2 \mathrm{C} 1 \mathrm{X}$ & \\
\hline & Medicago truncatula Flavonoid 3-o-glucosyltransferase (UGT78G1) & 3HBF & \\
\hline \multirow[t]{3}{*}{ UGT1A3 } & Streptomyces antibioticus oleandomycin glycosyltransferase & 2IYA & Yao et al., 2015; Liu X. et al., 2016 \\
\hline & Vitis vinifera UDP-glucose flavonoid 3-o glycosyltransferase (VvGTI) & $2 \mathrm{C} 1 \mathrm{X}$ & \\
\hline & Arabidopsis thaliana hydroquinone glucosyltransferase (UGT72B1) & 2VCE & \\
\hline UGT1A3 & Vitis vinifera UDP-glucose flavonoid 3-o glycosyltransferase (VvGTI) & $2 \mathrm{C} 1 \mathrm{Z}$ & Schirris et al., 2015 \\
\hline UGT1A8 and UGT1A9 & Amycolatopsis orientalis TDP-epi-vancosaminyltransferase (GtfA) & $1 \mathrm{PN} 3$ & Fujiwara et al., 2009a \\
\hline UGT1A9 & Vitis vinifera UDP-glucose flavonoid 3-o-glycosyltransferase (VvGTI) & $2 \mathrm{C} 1 \mathrm{Z}$ & Wu et al., 2012 \\
\hline \multirow[t]{2}{*}{ UGT1A9 } & Vitis vinifera UDP-glucose flavonoid 3-o-glycosyltransferase (VvGTI) & $2 \mathrm{C} 1 \mathrm{Z}$ & Li et al., 2016 \\
\hline & Homo sapiens UGT2B7 (C-terminal domain) & $206 \mathrm{~L}$ & \\
\hline \multirow[t]{4}{*}{ UGT1A9 and UGT1A10 } & Streptomyces antibioticus oleandomycin glycosyltransferase & 2IYA & Tripathi et al., 2016 \\
\hline & Streptomyces fradiae C-glycosyltransferase (UrdGT2) & 2P6P & \\
\hline & Medicago truncatula triterpene UDP-glucosyl transferase (UGT71G1) & 2ACV & \\
\hline & Homo sapiens UGT2B7 (C-terminal domain) & $206 \mathrm{~L}$ & \\
\hline UGT1A10 & Escherichia coli UDP-galactose 4-epimerase & 1XEL & Banerjee et al., 2008 \\
\hline \multirow[t]{3}{*}{ UGT2B7 } & Vitis vinifera UDP-glucose flavonoid 3-o-glycosyltransferase (VvGTI) & $2 \mathrm{C} 1 \mathrm{X}, 2 \mathrm{C} 1 \mathrm{Z}, 2 \mathrm{C} 9 \mathrm{Z}$ & Lewis et al., 2011; Chau et al., 2014 \\
\hline & Medicago truncatula triterpene UDP-glucosyl transferase (UGT71G1) & 2ACV, $2 \mathrm{ACW}$ & \\
\hline & Homo sapiens UGT2B7 (C-terminal domain) & $206 \mathrm{~L}$ & \\
\hline \multirow[t]{2}{*}{ UGT2B7 } & Streptomyces antibioticus oleandomycin glycosyltransferase & 2IYA & Zhang et al., 2016 \\
\hline & Medicago truncatula multifunctional (iso)flavonoid glycosyltransferase (UGT85H2) & 2PQ6 & \\
\hline $\begin{array}{l}\text { C-terminal domains of } \\
\text { UGT1, UGT2A1/2A2, } \\
\text { UGT2A3, UGT2B4, } \\
\text { UGT2B10, UGT2B11, } \\
\text { UGT2B15, UGT2B17, } \\
\text { UGT2B28 }\end{array}$ & Homo sapiens UGT2B7 (C-terminal domain) & $206 \mathrm{~L}$ & Nair et al., 2015 \\
\hline
\end{tabular}

Matern et al. (1982) similarly purified UGTs that catalyze chenodeoxycholic acid and testosterone glucuronidations from rat liver microsomes by a series of purification steps such as polyethylene glycol fractionation, DEAE-Sepharose CL-6B chromatography, UDP-hexanolamine-Sepharose 4B chromatography, and Bio-Gel A-1.5 m chromatography. While the molecular weight of subunit was determined to be $54 \mathrm{kDa}$ in the SDS-PAGE analysis, the apparent molecular weight of the enzyme was calculated to be $316 \mathrm{kDa}$ in a polyacrylamide gradient slab gel electrophoresis (Matern et al., 1982). The data indicated that rat UGTs were also present as tetrameric or even larger oligomeric forms.

\section{Radiation Inactivation}

Radiation inactivation is an analytical tool to determine molecular weights of membrane-bound enzymes in situ (Kempner and Schlegel, 1979). Enzymes are inactivated when they are irradiated with ionizing radiation. The extent of radiation-induced inactivation of the enzymes is directly associated with the radiation dose and the molecular weight of the concerned enzymes. Peters et al. (1984) determined the molecular weights of rat UGTs by radiation-inactivation of SDS-treated lyophilized liver microsomes using a calibrated ${ }^{60} \mathrm{Co}$ source. The radiation-inactivation analysis revealed that bilirubin mono-glucuronidation was catalyzed by a $41.5 \mathrm{kDa}$ protein, while bilirubin di-glucuronidation was catalyzed by a $175 \mathrm{kDa}$ protein. It was further demonstrated that proteins with molecular weight of 142 and $159 \mathrm{kDa}$ catalyzed glucuronidations of testosterone and phenolphthalein, respectively (Peters et al., 1984). Similarly, the radiation inactivation analysis by Gschaidmeier and Bock (1994) revealed that molecular weights of UGTs catalyzing the glucuronidations of 1-naphthol, 6-hydroxychrysene, 3,6-dihydroxybenzo[a]pyrene, and 3,6dihydroxychrysene were $91-218 \mathrm{kDa}$. The series of radiation 


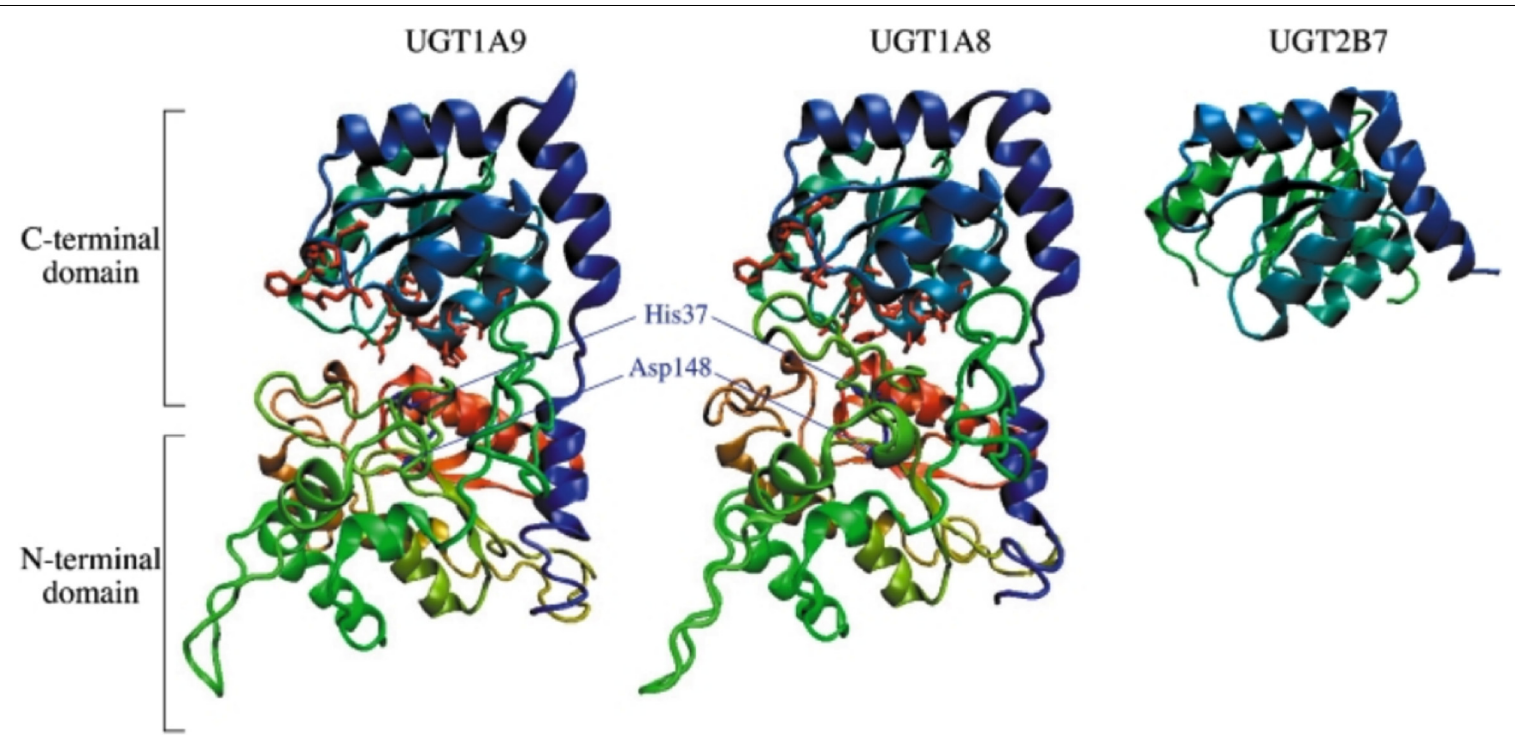

FIGURE 3 | Homology-modeled structures of human UGT1A9 and UGT1A8. Three-dimensional structures of human UGT1A9 and UGT1A8 were homology-modeled using Amycolatopsis orientalis GtfA (PDB ID: 1PN3) as template structures. The structures of UGT1A9 and UGT1A8 contain two Rossmann fold-like domains in the N-terminus and C-terminus. The structures are colored from red at the $\mathrm{N}$-terminal to blue at the $\mathrm{C}$-terminal. Amino acid residues that are predicted to interact with UDPGA and to be important for the catalysis are shown by red and blue licorice, respectively. The X-ray crystal structure of the C-terminal domain of UGT2B7 was retrieved from the Protein Data Bank (PDB ID: 2O6L). Adapted from Drug Metabolism and Pharmacokinetics (Fujiwara et al., 2009a).

inactivation analyses clearly demonstrated that mammalian UGTs were functional as oligomeric proteins that are composed of two to four subunits.

\section{Cross-Linking}

In intact cells, most of proteins are interacting with other protein(s) (Jeong et al., 2001). Upon the denaturing process in the SDS-PAGE analysis, such protein interactions via disulfide binding, hydrogen binding, and hydrophobic or salt-bridge interactions are disrupted, so that the proteins are separated according to their molecular weight. Cross-linkers are reagents that can introduce covalent chemical bonds between specific amino acids of proteins. Thus, proteins treated with crosslinkers can be observed as bands with higher molecular weights rather than their monomeric forms on SDS-PAGE followed by immunoblotting. Ikushiro et al. (1997) used 1,6bis(maleimido)hexane (BMH), which is a homobifunctional cross-linker that reacts with sulfhydryl-groups of proteins. When rat liver microsomes that were incubated with $\mathrm{BMH}$ and were applied to the SDS-PAGE followed by the immunoblotting analysis using anti UGT1 or UGT2B1 antibodies, multiple bands with molecular masses of $50-60 \mathrm{kDa}$ as well as of 120-130 kDa were observed (Ikushiro et al., 1997). They concluded that sulfhydryl group(s) of rat UGTs are located on the outside of the proteins and play a critical role in the formation of UGT dimers. Ghosh et al. (2001) used the disulfide cross-linker $\mathrm{BMH}$ and an amino group cross-linker dimethyl 3,3'-dithiobispropionimidate (DTBP) to demonstrate homo-oligomers of human UGT1A1, finding that both $\mathrm{BMH}$ and DTBT produced bands corresponding to homo-dimers of UGT1A1 on the SDS-PAGE analysis. The density of the bands was apparently reduced when UGT1A1-expressed cells were incubated with DTBP at $\mathrm{pH}$ 9.0, indicating that homodimerization of human UGT1A1 can be disrupted at alkaline $\mathrm{pH}$.

\section{Affinity Purification and Immunoprecipitations}

Immunopurification and immunoprecipitation are classical methods to identify proteins interacting with a target protein. When rat liver microsomes were solubilized in buffer containing 1\% Emulgen 913 and were applied to a UGT1 antibodyconjugated Sepharose 4B column, not only UGT1 isozymes but also unidentified $50-\mathrm{kDa}$ protein(s) were co-eluted by eluting solution containing UGT1A-peptides (Ikushiro et al., 1997). Amino acid sequencing of the $50-\mathrm{kDa}$ proteins and immunoblotting studies further revealed that the protein interacting with UGT1A was UGT2B1. Although the method used in a study by Kurkela et al. (2003) was Ni-column which is not immunopurification, they purified homo-oligomer of UGT1A9 that consisted of His- and hemagglutinin (HA)-tagged UGT1A9.

Fremont et al. (2005) conducted immunoprecipitation assays to examine protein-protein interactions between UGT1A1, UGT1A6, and UGT2B7 in human liver microsomes. When solubilized microsomes were incubated with UGT1A1-, UGT1A6-, and UGT2B7-specific antibodies, not only the antigenic proteins but also other UGT isozymes were coimmunoprecipitated. In 2007, we established cell lines that are individually or simultaneously expressing human UGT1A6 and UGT1A9 (Fujiwara et al., 2007b). A human UGT1A6specific antibody co-immunoprecipitated UGT1A9, as well 
as UGT1A6, in the UGT1A6-UGT1A9 double expression cells, although it did not immunoprecipitate UGT1A9 in the UGT1A9-expressed cells. When cyan fluorescent protein (CFP)and HA-tagged UGT1A1s were simultaneously expressed in COS cells, anti-HA beads immunoprecipitated both CFPand HA-tagged UGT1A1s (Operaña and Tukey, 2007). Taken together, immunoaffinity purification and immunoprecipitation assays are typical but still powerful tools to demonstrate homoand hetero-oligomerization of UGTs. Immunoprecipitation assays by Bellemare et al. (2010) further revealed that inactive UGT1A_i2 proteins form not only homo-oligomers (i2-i2) but also hetero-oligomers with UGT1A_i1 proteins (i1-i2).

\section{Fluorescence Resonance Energy Transfer (FRET)}

To examine UGT-UGT interactions in intact cells, Operaña and Tukey (2007) conducted a FRET analysis using cyan and yellow fluorescent proteins (CFP and YFP)-tagged recombinant human UGTs expressed in COS cells. When correction for donor and acceptor bleed through was performed and FRET signal was analyzed, it was revealed that the two fusion UGT proteins resided within ångströms from each other. Their FRET analysis demonstrated homo-oligomerization of all UGT1A isoforms as well as hetero-oligomerization of UGT1A1 with the other UGT1A isoforms. The FRET analysis conducted by a different research group indicated that not only UGT1As, but also human UGT2B7 formed homo-oligomers in SF9 cells (Yuan et al., 2015; Liu Y.Q. et al., 2016).

\section{REGIONS AND AMINO ACID RESIDUES RESPONSIBLE FOR OLIGOMERIZATION OF UGTs}

\section{Importance of $\mathbf{N}$-terminal Domain}

To examine the region responsible for the oligomerization of UGTs, Meech and Mackenzie (1997) constructed a couple of chimeric rat UGT2B1 proteins fused with ecdysteroid glucosyltransferase (EGT), which does not oligomerize. While intact UGT2B1 formed dimers, the dimerization was not observed when the C-terminal half of UGT2B1 was fused with the N-terminal half of EGT. In 2001, two-hybrid analysis by Ghosh et al. (2001) showed that UGT1A1s that were mutated or partially deleted in their $\mathrm{N}$-terminal region (L175E, C233Y, or del152-180) abolished the ability to form homo-oligomers, while UGT1A1 with partial truncation of the C-terminal (K530X) still formed homo-oligomers (Ghosh et al., 2001). These data indicated that the N-terminal domains are involved in oligomerization of mammalian UGTs.

\section{Hydrophobic Amino Acids on the Surface of Modeled UGT2B7}

Hydrophobic amino acid residues on the surface of proteins can mediate protein-protein interactions by introducing proline brackets and $\pi-\pi$ interactions. To identify such hydrophobic amino acid residues of UGTs, Lewis et al. (2011) obtained a three-dimensional structure of human UGT2B7 by homology modeling (Table 1). In the homology-modeled structure of human UGT2B7, a cluster of highly hydrophobic amino acid residues on a $\mathrm{B}^{\prime}-\mathrm{C}$ loop (amino acid residues 183-200) was located on the protein surface (Lewis et al., 2011). Thus, not only in vitro studies, but in silico structural analyses also supported the involvement of the N-terminal region of UGTs in oligomerization.

\section{PROTEIN-PROTEIN INTERACTIONS OF UGTS WITH OTHER PROTEINS}

\section{Protein Interactions with CYPs}

Cytochrome P450s are phase I drug-metabolizing enzymes that are expressed in the ER membrane. To investigate the possible protein-interactions between UGTs and CYPs, Taura et al. (2000) applied solubilized rat liver microsomes to a CYP1A1conjugated Sepharose 4B column. It was found that multiple UGT isoforms were co-eluted in a fraction where CYP1A1 was eluted. Rat UGTs were detected in immunoprecipitates when solubilized rat liver microsomes were reacted with specific antibodies against CYP3A2, CYP2B2, CYP2C11, and CYP1A2 (Ishii et al., 2007). Antibodies against human UGT2B7 and CYP3A4 immunoprecipitated not only their antigenic proteins but also CYP3A4 and UGT2B7, respectively, in solubilized human liver microsomes (Fremont et al., 2005; Takeda et al., 2005, 2009). These data indicate that mammalian UGTs interact with CYPs in liver microsomes. It remains to be determined whether such UGT-CYP interactions can still be observed in a reconstituted system.

\section{Protein Interactions with Microsomal Proteins}

Immunoprecipitation assay with human UGT2B7 antibody was conducted using solubilized human liver microsomes. The obtained immunoprecipitate was digested with trypsin, and the resulting peptides were analyzed by LC-MS/MS to identify proteins interacting with UGT2B7 in human liver microsomes (Fujiwara and Itoh, 2014). The extensive peptide analysis showed that the peptide sequences of UGT2B7, epoxide hydrolase 1, carboxylesterase 1, alcohol dehydrogenases, and glutathione $S$-transferases, as well as CYPs, were included in the immunoprecipitates. It was confirmed that such peptide sequences were not detected in immunoprecipitates obtained with a control rabbit IgG antibody. Therefore, UGT2B7 might be able to form a metabolosome, which is a functional unit of metabolism (Mori et al., 2011) in liver microsomes.

\section{Protein Interactions with Cytoplasmic Proteins}

In contrast to normal UGT1A proteins (UGT1A_i1) that are expressed in the luminal side of the ER membrane, a 
portion of UGT1A_i2 is cytoplasmic (Lévesque et al., 2007). Immunoprecipitates of solubilized human intestine and kidney homogenates with anti-UGT1A_i2 antibody were applied to a global peptide analysis (Rouleau et al., 2014). It was found that cytoplasmic catalase and peroxiredoxin 1 were coimmunoprecipitated with UGT1A_i2 proteins in both tissues, indicating that the truncated UGT1A isoform 2 is interacting with those cytoplasmic proteins. Since such protein-protein interactions were not observed when anti-UGT1A_i1 antibody was used, the interactions with cytoplasmic proteins would be specific to UGT1A_i2 proteins.

\section{PHYSIOLOGICAL SIGNIFICANCE OF OLIGOMERIZATION AND PROTEIN-PROTEIN INTERACTIONS OF UGTs}

\section{Impact of UGT-UGT Interactions on the UGT-Mediated Glucuronidations}

To investigate the effect of UGT-UGT interactions on the UGT activities, Ishii et al. (2001, 2004) cloned guinea pig UGT2B21 and UGT2B22 and examined morphine 6-O-glucuronidation in COS-7 cells expressing these UGTs. While UGT2B21 glucuronidates morphine, UGT2B22 does not have such ability to glucuronidate morphine. Morphine 6-glucuronide formation was 4.5-fold higher in COS-7 cells co-transfected with UGT2B21 and UGT2B22 compared to that in the cells transfected with UGT2B21 alone, indicating that protein-protein interactions between UGT2B21 and UGT2B22 upregulated the UGT activities (Ishii et al., 2001, 2004). This observation led us to investigate the impact of UGT-UGT interactions on the enzyme activities in humans (Fujiwara et al., 2007b; Nakajima et al., 2007). When we established stable expression systems of double human UGT1As in HEK293 cells, the $S_{50}$ value of UGT1A1mediated bilirubin glucuronidation was decreased by twofold by the co-expressions of UGT1A4 or UGT1A6 (Fujiwara et al., 2007a). A similar decrease of the $S_{50}$ value was observed in the UGT1A1-mediated estradiol 3-O-glucuronidation in a coexpression system of UGT1A1 and UGT2B7 in HEK293 cells (Fujiwara et al., 2010a). These data showed that substratebinding affinity of UGT1A1 toward bilirubin and estradiol was increased when UGT1A1 was co-expressed with UGT1A4, UGT1A6, and UGT2B7. Meanwhile, co-expression of UGT1A9 decreased the $V_{\max }$ value of UGT1A1-mediated estradiol 3-Oglucuronidation without affecting the $S_{50}$ value (Fujiwara et al., 2007b). Kurkela et al. (2004) demonstrated that the rate of UGT1A9-catalyzed scopoletin glucuronidation was significantly decreased by co-expression of UGT1A4. Thus, UGT-UGTinteractions can modulate the catalytic rate of glucuronidation as well as the affinity of substrates toward UGTs. Importantly, the effects are dependent on interacting UGT isoforms and compounds used as substrates.

Interestingly, even though sorafenib is mainly metabolized by UGT1A9, it was demonstrated that the AUC of sorafenib was twice higher in patients with UGT1A1 variants or with hyperbilirubinemia (Peer et al., 2012). This finding indicates that UGT1A1 might control the enzyme activity of UGT1A9 in vivo by interacting with UGT1A9.

Although UGT1A_i2 proteins carry a potential UDPglucuronic acid binding-site, they do not show substantial glucuronidation activity. As described above, the inactive UGT1A_i2 proteins form hetero-oligomers with functional UGT1A_i1 proteins. It was shown that glucuronide formation mediated by UGT1A_il proteins was significantly suppressed when UGT1A_i2 was co-expressed with UGT1A_i1 (Bellemare et al., 2010). The expression level and the ratio of UGT1A_i1 and _i2 are different in each tissue (Girard et al., 2007), suggesting that UGT1A_i2 can be a factor suppressing the glucuronidation in certain tissues. Interestingly, such suppression of UGT1 activity can also be caused by a truncated mutant of UGT1A1 (Gln331Stop; $\mathrm{C}$ to $\mathrm{T}$ at nucleotide 991), possibly by forming oligomers (Koiwai et al., 1996).

\section{Impact of UGT-CYP Interactions on the UGT Activities}

While a $K_{\mathrm{m}}$ value of morphine 3-glucuronide formation was $0.38 \mathrm{mM}$ in UGT2B7-expressing COS-1 cells, a much higher $K_{\mathrm{m}}$ value $(3.7 \mathrm{mM})$ was observed in UGT2B7 and CYP3A4 coexpressing cells (Takeda et al., 2005). In contrast, co-expression of CYP1A2 or CYP2C9 did not affect the kinetic parameters of UGT2B7-catalyzed morphine 3-glucuronide formations. In addition, co-expression of CYP3A4 increased a $K_{\mathrm{m}}$ value of UGT1A6-mediated serotonin glucuronidation by $\sim$ fourfold, whereas it barely affected $K_{\mathrm{m}}$ values of UGT1A1-mediated 4-MU, SN-38-, or estradiol 3-O-glucuronidations as well as UGT1A7-mediated 4-MU, SN-38-, and 4-hydroxybiphenylglucuronidations (Ishii et al., 2014). Meanwhile, co-expression of CYP3A4 increased $V_{\max }$ values of UGT1A1-mediated 4-MU, SN-38-, and estradiol 3-O-glucuronidations, UGT1A6-mediated serotonin glucuronidation, and UGT1A7-mediated 4-MU, SN38-, and 4-hydroxybiphenyl-glucuronidations, although it did not affect the UGT2B7-mediated morphine 3-glucuronidation (Takeda et al., 2005; Ishii et al., 2014). Therefore, CYP isoforms differently affect UGT-mediated glucuronidations and the effects are depending on UGT isoforms as well as their substrates.

\section{Effect UGTs on Other Physiological Functions}

Interestingly, a more than 40 -fold interindividual variability in UGT1A6-catalyzed serotonin glucuronidation was observed among individual human liver microsomes (Krishnaswamy et al., 2003, 2005). Such variability could not be explained even when the activities were normalized with the UGT1A6 content and its genetic polymorphisms, indicating that there might be some unidentified factor that is capable of modulating the UGT1A6 activity. Since CYP isoforms can modulate UGT activities in different ways, interindividual variability in the CYP expression and function might be one of the causes of these wide interindividual variabilities in UGT1A6-catalyzed serotonin glucuronidation. 
Miyauchi et al. (2015) investigated the effect of UGT2B7 on CYP3A4 activities by establishing a co-expression system of UGT2B7 and CYP3A4. They found that co-expression of UGT2B7 significantly decreased the $V_{\max }$ value of CYP3A4 activity without affecting a $K_{\mathrm{m}}$ value using luciferin-6'pentafluorobenzyl ether as a substrate. Similarly, co-expression of UGT2B7 decreased the CYP3A4-mediated testosterone $6 \beta$ hydroxylation at a single substrate concentration (Miyauchi et al., 2015). These observations indicated that UGTs might suppress the enzyme activities of CYPs.

In a recent study by Liu M. et al. (2016), it was demonstrated that silencing of UGT1A expressions led to inhibitions of actinomycin D- and etoposide-induced p53 expressions in human colon HT29 and LS180 cells. Tissue-specific deletion of the Ugt1 locus in intestinal crypt stem cells not only reduced p53 activation, but also compromised apoptosis. It was further demonstrated that reduced expression of UGT1A in intestine caused greater size and number of tumors in the colon cancer models (Liu M. et al., 2016).

When UGT1A_i2 was knocked-down in colorectal carcinoma-derived HT115 cells, expressions of a number of genes were up- or down-regulated (Rouleau et al., 2014). Among those genes, hemoglobin-alpha was significantly induced by the knockdown of UGT1A_i2. The function of hemoglobin-alpha proteins has been linked to cellular antioxidant potential (Widmer et al., 2010). Furthermore, it was found that knocked-down of UGT1A_i2 reduced a chemicalinduced ROS formation in HT115 cells and significantly induced superoxide dismutase 1, an antioxidative gene. Although the underlying mechanism of induction of hemoglobin-alpha by knockdown of UGT1A_i2 is still unknown, the observation clearly indicates that UGT1A_i2 proteins are involved in the regulation of oxidative stress in cells. Taking all these findings together, it appears that UGTs are multifunctional proteins that controls metabolism, cell death and development of tumors, and oxidative stress.

\section{CRITIQUE AND FUTURE RESEARCH DIRECTIONS}

\section{Protein Structure of UGTs}

Various three-dimensional structures of human UGTs have been simulated by homology modeling (Table 1) and they are relatively acceptable as mentioned above. However, due to the extremely low amino acid similarity and different length of the amino acid sequence between human UGTs and template plant and bacterial UGTs, the reliability of the modeled human UGT protein structures is still an open question. Indeed, it is generally believed that the identity of amino acid sequence with the template needs to be more than $70 \%$ to obtain reliable structure. Furthermore, there is a significant structural difference between human and plant/bacterial UGTs that human UGTs are membrane proteins while plant and bacterial UGTs are not. To obtain a completely reliable modeled structure of human UGTs, an X-ray crystal structure of human UGTs needs to be successfully solved. Importantly, as mammalian UGTs abolish their enzyme activities when they are solubilized, a solubilized and crystallized structure of human UGTs might be an enzymatically inactive form. The instability of the protein structure of human UGTs can also be an obstacle in crystallizing them. Interestingly, UGT1A9 solely exhibited its enzymatic activity in the presence of $0.2 \%$ Triton X-100, although activities of other UGT1A and 2B isoforms were abolished by the detergent treatment (Kurkela et al., 2003). Human UGT1A9 is uniquely stable against a heat treatment as well (Fujiwara et al., 2009a), indicating that the protein structure of UGT1A9 must be more stable than the structures of other UGT isoforms. Therefore, human UGT1A9 is a promising human UGT isoform that has a potential to be crystallized as an active form.

\section{Oligomerization of UGTs In vivo}

Gel filtration and radiation inactivation analyses, where the liver microsomes were mixed with detergents, showed that monomeric UGTs catalyzed glucuronidation of certain compounds. It is well known that detergents can disrupt oligomerization of proteins; therefore, the monomeric UGTs might have been artificially generated from disruption of UGT oligomers. While SDS-PAGE shows the molecular weight of individual subunits of proteins under the reduced and denatured condition, oligomerization can be preserved in native-PAGE analysis. Our native-PAGE analysis of recombinant human UGTs expressed in HEK293 cells showed that most of UGTs were present as monomers, whereas some of them were still forming oligomers (Figure 4) (Fujiwara et al., 2007a). However, again, such monomers could have been a result from disruption of oligomeric UGTs due to a fact that the native-PAGE experiment required $1 \%$ Triton X-100 and $0.2 \%$ SDS to slightly solubilize the cell homogenates. Therefore, it is unclear whether UGTs dominantly exist as oligomer or monomer in intact cells.

Fluorescence resonance energy transfer is an analytical tool to demonstrate oligomerization of proteins in intact cells. Interestingly, FRET efficiency, which is a marker for colocalization and interaction, was $90 \%$ in COS cells expressing CFP- and YFP-tagged UGT1A7s (Operaña and Tukey, 2007), indicating that most of UGT1A7 was interacting with each other to form oligomers in intact cells. Meanwhile, the FRET efficiency was lower in certain UGT1A isoforms such as UGT1A3 and UGT1A9. These observations indicate that UGTs would exist as both monomeric and oligomeric forms in intact cells with variable extent depending on UGT isoforms. A limitation of the FRET analysis is that tagged UGT proteins, not intact proteins, were used. Therefore, determination of the extent of monomeric/oligomeric forms of intact UGT in cellulo is a future issue.

\section{Availability and Application of Ugt1 and Ugt2 Knockout Mice}

Various data indicate that UGTs can be multifunctional proteins that are involved in cellular metabolism, apoptosis, carcinogenesis, and oxidative stress as well as glucuronidation. 


Single
expression
systems
(x 10-2 unit)

However, these unique properties of UGTs have not been fully validated by in vivo data. Ugt1- and Ugt2-knockout animals are promising in vivo models for investigating the roles of UGTs in such cellular metabolism, apoptosis, carcinogenesis, and oxidative stress. With extensive efforts by Drs. Tukey and Koller and their colleagues, Ugt1- and Ugt2-knockout mice were previously developed in 2008 and 2015, respectively (Nguyen et al., 2008; Fay et al., 2015). While Ugt2 knockout mice can be used for the phenotype analysis, Ugt1 knockout mice are lethal within 11 days after birth due to development of a bilirubin-induced irreversible brain damage, kernicterus. To conduct phenotype analyses in Ugt1 knockout mice, therefore, we need to first avoid the lethality of the mice. Inhibitors of bilirubin production and inducers of bilirubin clearance might have potentials to rescue the lethality of the Ugt1 knockout mice.

\section{Possible Role of UGTs in Transport of UGT Substrates and Metabolites}

Transporters responsible for the uptake of the co-substrate UDP-glucuronic acid from cytosol to the luminal side of ER membrane have been identified (Muraoka et al., 2001). Although studies suggested that there are proteins that are involved in the efflux of hydrophilic glucuronide across the ER membrane (Bánhegyi et al., 1996; Csala et al., 2004), such transporter(s) has not been identified. As shown in Figure 5, it was originally hypothesized that oligomerization and/or proteinprotein interactions of UGTs have a role in transporting glucuronides across the ER membrane (Lin and Wong, 2002; Ishii et al., 2005); however, such evidence has not yet been obtained. Even in the immunoprecipitates of liver microsomes with anti-UGT2B7 antibody, no peptide sequences of transporters was observed (Fujiwara and Itoh, 2014). Further studies are required to fully understand the detailed information on the

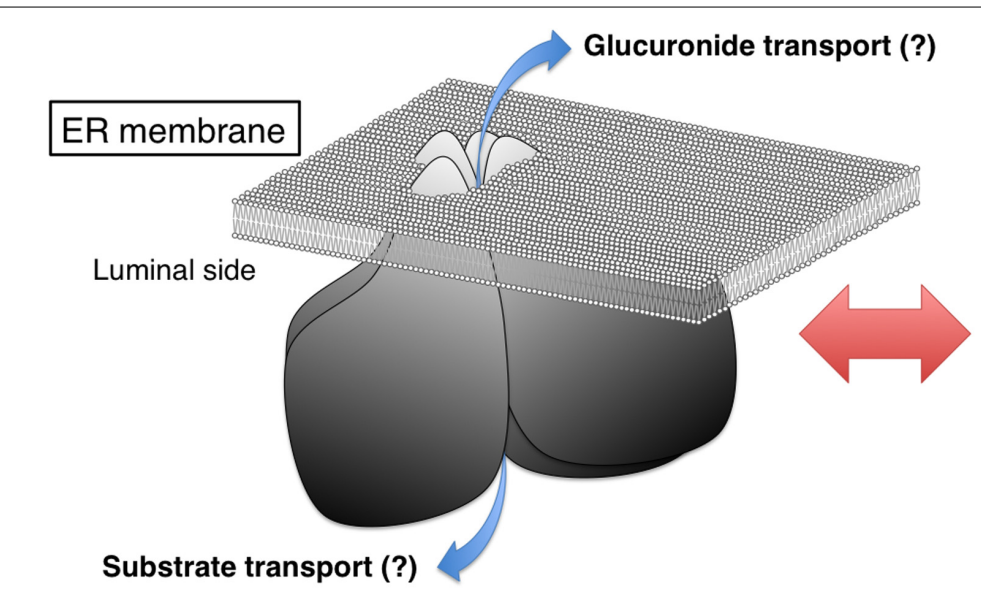

UGT (Glucuronidation)

CYP (Oxidation)

p53 (apoptosis and carcinogenesis)

Cytoplasmic proteins (Oxidative stress)

Microsomal proteins

\section{Oligomeric UGTs}

FIGURE 5 | Proposed model of oligomeric human UGTs. Human UGTs form homo- and hetero-oligomers in ER membrane. As indicated with blue arrows, oligomerization of UGTs might be involved in the transport of substrates and glucuronides across the ER membrane. Protein-protein interactions of human UGT with other microsomal and cytoplasmic proteins such as UGT, CYP, and p53 can make a great impact on glucuronidation, oxidation, apoptosis, carcinogenesis, and oxidative stress. 
transport of UGT substrates and their metabolites across the ER membrane.

\section{CONCLUSION}

In addition to enzyme inhibition and induction, oligomerization is a predominant factor regulating the function of UGTs. UGTs are multifunctional proteins that are involved not only in glucuronidation, but also in cellular metabolism, apoptosis, carcinogenesis, and oxidative stress in the human body (Figure 5). Global protein interactions of UGTs with other microsomal or cytoplasmic proteins might be a contributing

\section{REFERENCES}

Banerjee, R., Pennington, M. W., Garza, A., and Owens, I. S. (2008). Mapping the UDP-glucuronic acid binding site in UDP-glucuronosyltransferase-1A10 by homology-based modeling: confirmation with biochemical evidence. Biochemistry 47, 7385-7392. doi: 10.1021/bi8006127

Bánhegyi, G., Braun, L., Marcolongo, P., Csala, M., Fulceri, R., Mandl, J., et al. (1996). Evidence for an UDP-glucuronic acid/phenol glucuronide antiport in rat liver microsomal vesicles. Biochem. J. 315, 171-176. doi: 10.1042/bj31 50171

Barbier, O., Turgeon, D., Girard, C., Green, M. D., Tephly, T. R., Hum, D. W., et al. (2000). $3^{\prime}$-azido-3'-deoxythimidine (AZT) is glucuronidated by human UDPglucuronosyltransferase 2B7 (UGT2B7). Drug Metab. Dispos. 28, 497-502.

Bellemare, J., Rouleau, M., Harvey, M., and Guillemette, C. (2010). Modulation of the human glucuronosyltransferase UGT1A pathway by splice isoform polypeptides is mediated through protein-protein interactions. J. Biol. Chem. 285, 3600-3607. doi: 10.1074/jbc.M109.083139

Bernard, O., and Guillemette, C. (2004). The main role of UGT1A9 in the hepatic metabolism of mycophenolic acid and the effects of naturally occurring variants. Drug Metab. Dispos. 32, 775-778. doi: 10.1124/dmd.32.8.775

Beutler, E., Gelbart, T., and Demina, A. (1998). Racial variability in the UDPglucuronosyltransferase 1 (UGT1A1) promoter: a balanced polymorphism for regulation of bilirubin metabolism? Proc. Natl. Acad. Sci. U.S.A. 95, 8170-8174. doi: 10.1073/pnas.95.14.8170

Bosma, P. J., Seppen, J., Goldhoorn, B., Bakker, C., Elferink, R. O., Chowdhury, J. R., et al. (1994). Bilirubin UDP-glucuronosyltransferase 1 is the only relevant bilirubin glucuronidating isoform in man. J. Biol. Chem. 269, 17960-17964.

Chau, N., Elliot, D. J., Lewis, B. C., Burns, K., Johnston, M. R., Mackenzie, P. I., et al. (2014). Morphine glucuronidation and glucosidation represent complementary metabolic pathways that are both catalyzed by UDPglucuronosyltransferase 2B7: kinetic, inhibition, and molecular modeling studies. J. Pharmacol. Exp. Ther. 349, 126-137. doi: 10.1124/jpet.113. 212258

Chen, S., Yueh, M. F., Bigo, C., Barbier, O., Wang, K., Karin, M., et al. (2013). Intestinal glucuronidation protects against chemotherapy-induced toxicity by irinotecan (CPT-11). Proc. Natl. Acad. Sci. U.S.A. 110, 19143-19148. doi: $10.1073 /$ pnas. 1319123110

Court, M. H. (2005). Isoform-selective probe substrates for in vitro studies of human UDP-glucuronosyltransferases. Methods Enzymol. 400, 104-116. doi: 10.1016/S0076-6879(05)00007-8

Csala, M., Staines, A. G., Bánhegyi, G., Mandl, J., Coughtrie, M. W., and Burchell, B. (2004). Evidence for multiple glucuronide transporters in rat liver microsomes. Biochem. Pharmacol. 68, 1353-1362. doi: 10.1016/j.bcp.2004.05.055

Fay, M. J., Nguyen, M. T., Snouwaert, J. N., Dye, R., Grant, D. J., Bodnar, W. M., et al. (2015). Xenobiotic metabolism in mice lacking the UDPglucuronosyltransferase 2 family. Drug Metab. Dispos. 43, 1838-1846. doi: 10.1124/dmd.115.065482

Finel, M., and Kurkela, M. (2008). The UDP-glucuronosyltransferases as oligomeric enzymes. Curr. Drug Metab. 9, 70-76. doi: 10.2174/138920008 783331158 factor to a wide interindividual variability in UGT-catalyzed glucuronidations.

\section{AUTHOR CONTRIBUTIONS}

All authors listed, have made substantial, direct and intellectual contribution to the work, and approved it for publication.

\section{ACKNOWLEDGMENT}

This work was partly supported by the Naito Foundation (RF).

Fremont, J. J., Wang, R. W., and King, C. D. (2005). Coimmunoprecipitation of UDP-glucuronosyltransferase isoforms and cytochrome P450 3A4. Mol. Pharmacol. 67, 260-262. doi: 10.1124/mol.104.006361

Fujiwara, R., Chen, S., Karin, M., and Tukey, R. H. (2012). Reduced expression of UGT1A1 in intestines of humanized UGT1 mice via inactivation of NF-кB leads to hyperbilirubinemia. Gastroenterology 142, 109-118. doi: 10.1053/j.gastro.2011.09.045

Fujiwara, R., and Itoh, T. (2014). Extensive protein-protein interactions involving UDP-glucuronosyltransferase (UGT) 2B7 in human liver microsomes. Drug Metab. Pharmacokinet. 29, 259-265. doi: 10.2133/dmpk.DMPK-13-RG-096

Fujiwara, R., Maruo, Y., Chen, S., and Tukey, R. H. (2015). Role of extrahepatic UDP-glucuronosyltransferase 1A1: advances in understanding breast milkinduced neonatal hyperbilirubinemia. Toxicol. Appl. Pharmacol. 289, 124-132. doi: 10.1016/j.taap.2015.08.018

Fujiwara, R., Nakajima, M., Oda, S., Yamanaka, H., Ikushiro, S. I., Sakaki, T., et al. (2010a). Interactions between human UDP-glucuronosyltransferase (UGT) 2 B7 and UGT1A enzymes. J. Pharm. Sci. 99, 442-454. doi: 10.1002/jps. 21830

Fujiwara, R., Nakajima, M., Yamamoto, T., Nagao, H., and Yokoi, T. (2009a). In silico and in vitro approaches to elucidate the thermal stability of human UDPglucuronosyltransferase (UGT) 1A9. Drug Metab. Pharmacokinet. 24, 235-244. doi: $10.2133 / \mathrm{dmpk} .24 .235$

Fujiwara, R., Nakajima, M., Yamanaka, H., Katoh, M., and Yokoi, T. (2007a). Interactions between human UGT1A1, UGT1A4, and UGT1A6 affect their enzymatic activities. Drug Metab. Dispos. 35, 1781-1787. doi: 10.1124/dmd.107.016402

Fujiwara, R., Nakajima, M., Yamanaka, H., Nakamura, A., Katoh, M., Ikushiro, S., et al. (2007b). Effects of coexpression of UGT1A9 on enzymatic activities of human UGT1A isoforms. Drug Metab. Dispos. 35, 747-757.

Fujiwara, R., Nakajima, M., Yamanaka, H., and Yokoi, T. (2009b). Key amino acid residues responsible for the differences in substrate specificity of human UDP-glucuronosyltransferase (UGT) 1 A9 and UGT1A8. Drug Metab. Dispos. 37, 41-46. doi: 10.1124/dmd.108.022913

Fujiwara, R., Nguyen, N., Chen, S., and Tukey, R. H. (2010b). Developmental hyperbilirubinemia and CNS toxicity in mice humanized with the UDP glucuronosyltransferase 1 (UGT1) locus. Proc. Natl. Acad. Sci. U.S.A. 107, 5024-5029. doi: 10.1073/pnas.0913290107

Ghosh, S. S., Sappal, B. S., Kalpana, G. V., Lee, S. W., Chowdhury, J. R., and Chowdhury, N. R. (2001). Homodimerization of human bilirubin-uridinediphosphoglucuronate glucuronosyltransferase-1 (UGT1A1) and its functional implications. J. Biol. Chem. 276, 42108-42115. doi: 10.1074/jbc.M1067 42200

Girard, H., Lévesque, E., Bellemare, J., Journault, K., Caillier, B., and Guillemette, C. (2007). Genetic diversity at the UGT1 locus is amplified by a novel $3^{\prime}$ alternative splicing mechanism leading to nine additional UGT1A proteins that act as regulators of glucuronidation activity. Pharmacogenet. Genomics 17, 10771089. doi: 10.1097/FPC.0b013e3282f1f118

Gschaidmeier, H., and Bock, K. W. (1994). Radiation inactivation analysis of microsomal UDP-glucuronosyltransferases catalysing mono-and diglucuronide formation of 3, 6-dihydroxybenzo (a) pyrene and 
3, 6-dihydroxychrysene. Biochem. Pharmacol. 48, 1545-1549. doi: 10.1016/0006-2952(94)90198-8

Hanioka, N., Jinno, H., Tanaka-Kagawa, T., Nishimura, T., and Ando, M. (2001). Determination of UDP-glucuronosyltransferase UGT1A6 activity in human and rat liver microsomes by HPLC with UV detection. J. Pharm. Biomed. Anal. 25, 65-75. doi: 10.1016/S0731-7085(00)00491-X

Hirashima, R., Michimae, H., Takemoto, H., Sasaki, A., Kobayashi, Y., Itoh, T., et al. (2016). Induction of the UDP-glucuronosyltransferase $1 \mathrm{~A} 1$ during the perinatal period can cause neurodevelopmental toxicity. Mol. Pharmacol. 90, 265-274. doi: 10.1124/mol.116.104174

Ikushiro, S., Emi, Y., and Iyanagi, T. (1997). Protein-protein interactions between UDP-glucuronosyltransferase isozymes in rat hepatic microsomes. Biochemistry 36, 7154-7161. doi: 10.1021/bi9702344

Ishii, Y., Iwanaga, M., Nishimura, Y., Takeda, S., Ikushiro, S. I., Nagata, K., et al. (2007). Protein-protein interactions between rat hepatic cytochromes P450 (P450s) and UDP-glucuronosyltransferases (UGTs): evidence for the functionally active UGT in P450-UGT complex. Drug Metab. Pharmacokinet. 22, 367-376. doi: 10.2133/dmpk.22.367

Ishii, Y., Koba, H., Kinoshita, K., Oizaki, T., Iwamoto, Y., Takeda, S., et al. (2014). Alteration of the function of the UDP-glucuronosyltransferase 1 A subfamily by cytochrome P450 3A4: different susceptibility for UGT isoforms and UGT1A1/7 variants. Drug Metab. Dispos. 42, 229-238. doi: 10.1124/dmd.113.054833

Ishii, Y., Miyoshi, A., Maji, D., Yamada, H., and Oguri, K. (2004). Simultaneous expression of guinea pig UDP-glucuronosyltransferase 2B21 (UGT2B21) and 2 B22 in COS-7 cells enhances UGT2B21-catalyzed chloramphenicol glucuronidation. Drug Metab. Dispos. 32, 1057-1060. doi: 10.1124/dmd.32.10

Ishii, Y., Miyoshi, A., Watanabe, R., Tsuruda, K., Tsuda, M., YamaguchiNagamatsu, Y., et al. (2001). Simultaneous expression of guinea pig UDPglucuronosyltransferase $2 \mathrm{~B} 21$ and $2 \mathrm{~B} 22$ in COS-7 cells enhances UDPglucuronosyltransferase 2B21-catalyzed morphine-6-glucuronide formation. Mol. Pharmacol. 60, 1040-1048.

Ishii, Y., Takeda, S., Yamada, H., and Oguri, K. (2005). Functional proteinprotein interaction of drug metabolizing enzymes. Front. Biosci. 10:887-895. doi: $10.2741 / 1583$

Izukawa, T., Nakajima, M., Fujiwara, R., Yamanaka, H., Fukami, T., Takamiya, M., et al. (2009). Quantitative analysis of UDP-glucuronosyltransferase (UGT) 1A and UGT2B expression levels in human livers. Drug Metab. Dispos. 37, 1759-1768. doi: 10.1124/dmd.109.027227

Jancova, P., Anzenbacher, P., and Anzenbacherova, E. (2010). Phase II drug metabolizing enzymes. Biomed. Pap. Med. Fac. Univ. Palacky Olomouc. Czech. Repub. 154, 103-116. doi: 10.5507/bp.2010.017

Jeong, H., Mason, S. P., Barabási, A. L., and Oltvai, Z. N. (2001). Lethality and centrality in protein networks. Nature 411, 41-42. doi: 10.1038/35075138

Kato, Y., Izukawa, T., Oda, S., Fukami, T., Finel, M., Yokoi, T., et al. (2013). Human UDP-glucuronosyltransferase (UGT) 2B10 in drug N-glucuronidation: substrate screening and comparison with UGT1A3 and UGT1A4. Drug Metab. Dispos. 41, 1389-1397. doi: 10.1124/dmd.113.051565

Kempner, E. S., and Schlegel, W. (1979). Size determination of enzymes by radiation inactivation. Anal. Biochem. 92, 2-10. doi: 10.1016/00032697(79)90617-1

Kerdpin, O., Mackenzie, P. I., Bowalgaha, K., Finel, M., and Miners, J. O. (2009). Influence of $\mathrm{N}$-terminal domain histidine and proline residues on the substrate selectivities of human UDP-glucuronosyltransferase 1A1, 1A6, 1A9, 2B7, and 2B10. Drug Metab. Dispos. 37, 1948-1955. doi: 10.1124/dmd.109. 028225

Koiwai, O., Aono, S., Adachi, Y., Kamisako, T., Yasui, Y., Nishizawa, M., et al. (1996). Crigler-Najjar syndrome type II is inherited both as a dominant and as a recessive trait. Hum. Mol. Genet. 5, 645-647. doi: 10.1093/hmg/5.5.645

Krishnaswamy, S., Duan, S. X., von Moltke, L. L., and Greenblatt, D. J. (2003). Validation of serotonin (5-hydroxtryptamine) as an in vitro substrate probe for human UDP-glucuronosyltransferase (UGT) 1A6. Drug Metab. Dispos. 31, 133-139. doi: 10.1124/dmd.31.1.133

Krishnaswamy, S., Hao, Q., Al-Rohaimi, A., Hesse, L. M., von Moltke, L. L., and Greenblatt, D. J. (2005). UDP glucuronosyltransferase (UGT) 1A6 pharmacogenetics: II. Functional impact of the three most common nonsynonymous UGT1A6 polymorphisms (S7A, T181A, and R184S). J. Pharmacol. Exp. Ther. 313, 1340-1346. doi: 10.1124/jpet.104.081968
Kuehl, G. E., and Murphy, S. E. (2003). N-glucuronidation of nicotine and cotinine by human liver microsomes and heterologously expressed UDP-glucuronosyltransferases. Drug Metab. Dispos. 31, 1361-1368. doi: 10.1124/dmd.31.11.1361

Kurkela, M., García-Horsman, J. A., Luukkanen, L., Mörsky, S., Taskinen, J., Baumann, M., et al. (2003). Expression and characterization of recombinant human UDP-glucuronosyltransferases (UGTs) UGT1A9. UGT1A9 is more resistant to detergent inhibition than other UGTs and was purified as an active dimeric enzyme. J. Biol. Chem. 278, 3536-3544. doi: 10.1074/jbc.M2061 36200

Kurkela, M., Hirvonen, J., Kostiainen, R., and Finel, M. (2004). The interactions between the N-terminal and C-terminal domains of the human UDPglucuronosyltransferases are partly isoform-specific, and may involve both monomers. Biochem. Pharmacol. 68, 2443-2450. doi: 10.1016/j.bcp.2004.08.019

Kutsuno, Y., Hirashima, R., Sakamoto, M., Ushikubo, H., Michimae, H., Itoh, T., et al. (2015). Expression of UDP-glucuronosyltransferase 1 (UGT1) and glucuronidation activity toward endogenous substances in humanized UGT1 mouse brain. Drug Metab. Dispos. 43, 1071-1076. doi: 10.1124/dmd.115.063719

Laakkonen, L., and Finel, M. (2010). A molecular model of the human UDPglucuronosyltransferase 1A1, its membrane orientation, and the interactions between different parts of the enzyme. Mol. Pharmacol. 77, 931-939. doi: 10.1124/mol.109.063289

Lankisch, T. O., Behrens, G., Ehmer, U., Möbius, U., Rockstroh, J., Wehmeier, M., et al. (2009). Gilbert's syndrome and hyperbilirubinemia in protease inhibitor therapy-an extended haplotype of genetic variants increases risk in indinavir treatment. J. Hepatol. 50, 1010-1018. doi: 10.1016/S0168-8278(09)61009-6

Lévesque, E., Girard, H., Journault, K., Lépine, J., and Guillemette, C. (2007). Regulation of the UGT1A1 bilirubin-conjugating pathway: role of a new splicing event at the UGT1A locus. Hepatology 45, 128-138. doi: 10.1002/hep.21464

Lewis, B. C., Mackenzie, P. I., and Miners, J. O. (2011). Homodimerization of UDP-glucuronosyltransferase 2B7 (UGT2B7) and identification of a putative dimerization domain by protein homology modeling. Biochem. Pharmacol. 82, 2016-2023. doi: 10.1016/j.bcp.2011.09.007

$\mathrm{Li}, \mathrm{C}$, and $\mathrm{Wu}, \mathrm{Q}$. (2007). Adaptive evolution of multiple-variable exons and structural diversity of drug-metabolizing enzymes. BMC Evol. Biol. 7:69. doi: 10.1186/1471-2148-7-1

Li, L., Huang, X. J., Peng, J. L., Zheng, M. Y., Zhong, D. F., Zhang, C. F., et al. (2016). Wedelolactone metabolism in rats through regioselective glucuronidation catalyzed by uridine diphosphate-glucuronosyltransferases 1As (UGT1As). Phytomedicine 23, 340-349. doi: 10.1016/j.phymed.2016.01.007

Lin, J. H., and Wong, B. K. (2002). Complexities of glucuronidation affecting in vitro in vivo extrapolation. Curr. Drug Metab. 3, 623-646. doi: $10.2174 / 1389200023336992$

Liu, M., Chen, S., Yueh, M. F., Wang, G., Hao, H., and Tukey, R. H. (2016). Reduction of p53 by knockdown of the UGT1 locus in colon epithelial cells causes an increase in tumorigenesis. Cell Mol. Gastroenterol. Hepatol. 2, 63-76. doi: 10.1016/j.jcmgh.2015.08.008

Liu, X., Cao, Y. F., Ran, R. X., Dong, P. P., Gonzalez, F. J., Wu, X., et al. (2016). New insights into the risk of phthalates: Inhibition of UDP-glucuronosyltransferases. Chemosphere 144, 1966-1972. doi: 10.1016/j.chemosphere.2015.10.076

Liu, Y. Q., Yuan, L. M., Gao, Z. Z., Xiao, Y. S., Sun, H. Y., Yu, L. S., et al. (2016). Dimerization of human uridine diphosphate glucuronosyltransferase allozymes $1 \mathrm{~A} 1$ and $1 \mathrm{~A} 9$ alters their quercetin glucuronidation activities. Sci Rep 6:23763. doi: $10.1038 /$ srep 23763

Locuson, C. W., and Tracy, T. S. (2007). Comparative modelling of the human UDP-glucuronosyltransferases: insights into structure and mechanism. Xenobiotica 37, 155-168. doi: 10.1080/00498250601129109

Mackenzie, P. I., Bock, K. W., Burchell, B., Guillemette, C., Ikushiro, S. I., Iyanagi, T., et al. (2005). Nomenclature update for the mammalian UDP glycosyltransferase (UGT) gene superfamily. Pharmacogenet. Genomics 15, 677-685. doi: 10.1097/01.fpc.0000173483.13689.56

Mackenzie, P. I., Owens, I. S., Burchell, B., Bock, K. W., Bairoch, A., Belanger, A., et al. (1997). The UDP glycosyltransferase gene superfamily: recommended nomenclature update based on evolutionary divergence. Pharmacogenet Genomics 7, 255-269. doi: 10.1097/00008571-199708000-00001

Mano, Y., Usui, T., and Kamimura, H. (2004). Effects of $\beta$-estradiol and propofol on the 4-methylumbelliferone glucuronidation in recombinant human UGT 
isozymes 1A1, 1A8 and 1A9. Biopharm. Drug Dispos. 25, 339-344. doi: $10.1002 /$ bdd. 418

Matern, H., Matern, S., and Gerok, W. (1982). Isolation and characterization of rat liver microsomal UDP-glucuronosyltransferase activity toward chenodeoxycholic acid and testosterone as a single form of enzyme. J. Biol. Chem. 257, 7422-7429.

Meech, R., and Mackenzie, P. I. (1997). UDP-glucuronosyltransferase, the role of the amino terminus in dimerization. J. Biol. Chem. 272, 26913-26917. doi: 10.1074/jbc.272.43.26913

Ménard, V., Eap, O., Roberge, J., Harvey, M., Levesque, E., and Guillemette, C. (2011). Transcriptional diversity at the UGT2B7 locus is dictated by extensive pre-mRNA splicing mechanisms that give rise to multiple mRNA splice variants. Pharmacogenet. Genomics 21, 631-641. doi: 10.1097/FPC.0b013e3283498147

Miley, M. J., Zielinska, A. K., Keenan, J. E., Bratton, S. M., Radominska-Pandya, A., and Redinbo, M. R. (2007). Crystal structure of the cofactor-binding domain of the human phase II drug-metabolism enzyme UDP-glucuronosyltransferase 2B7. J. Mol. Biol. 369, 498-511. doi: 10.1016/j.jmb.2007.03.066

Miners, J. O., Mackenzie, P. I., and Knights, K. M. (2010). The prediction of drug-glucuronidation parameters in humans: UDP-glucuronosyltransferase enzyme-selective substrate and inhibitor probes for reaction phenotyping and in vitro-in vivo extrapolation of drug clearance and drug-drug interaction potential. Drug Metab. Rev. 42, 196-208. doi: 10.3109/03602530903 210716

Miyauchi, Y., Nagata, K., Yamazoe, Y., Mackenzie, P. I., Yamada, H., and Ishii, Y. (2015). Suppression of cytochrome P450 3A4 function by UDPglucuronosyltransferase $2 \mathrm{~B} 7$ through a protein-protein interaction: cooperative roles of the cytosolic carboxyl-terminal domain and the luminal anchoring region. Mol. Pharmacol. 88, 800-812. doi: 10.1124/mol.115.098582

Mizuma, T. (2009). Intestinal glucuronidation metabolism may have a greater impact on oral bioavailability than hepatic glucuronidation metabolism in humans: a study with raloxifene, substrate for UGT1A1, 1A8, 1A9, and 1A10. Int. J. Pharm. 378, 140-141. doi: 10.1016/j.ijpharm.2009.05.044

Mori, Y., Kiyonaka, S., and Kanai, Y. (2011). Transportsomes and channelsomes: are they functional units for physiological responses? Channels 5, 387-390. doi: 10.4161/chan.5.5.16466

Mulichak, A. M., Losey, H. C., Lu, W., Wawrzak, Z., Walsh, C. T., and Garavito, R. M. (2003). Structure of the TDP-epi-vancosaminyltransferase GtfA from the chloroeremomycin biosynthetic pathway. Proc. Natl. Acad. Sci. U.S.A. 100, 9238-9243. doi: 10.1073/pnas.1233577100

Muraoka, M., Kawakita, M., and Ishida, N. (2001). Molecular characterization of human UDP-glucuronic acid/UDP-N-acetylgalactosamine transporter, a novel nucleotide sugar transporter with dual substrate specificity. FEBS Lett. 495, 87-93. doi: 10.1016/S0014-5793(01)02358-4

Nair, P. C., Meech, R., Mackenzie, P. I., McKinnon, R. A., and Miners, J. O. (2015). Insights into the UDP-sugar selectivities of human UDP-glycosyltransferases (UGT): a molecular modeling perspective. Drug Metab. Rev. 47, 335-345. doi: 10.3109/03602532.2015.1071835

Nakajima, M., Yamanaka, H., Fujiwara, R., Katoh, M., and Yokoi, T. (2007). Stereoselective glucuronidation of 5-(4'-hydroxyphenyl)-5-phenylhydantoin by human UDP-glucuronosyltransferase (UGT) 1A1, UGT1A9, and UGT2B15: effects of UGT-UGT interactions. Drug Metab. Dispos. 35, 1679-1686. doi: 10.1124/dmd.107.015909

Nakamura, A., Nakajima, M., Yamanaka, H., Fujiwara, R., and Yokoi, T. (2008). Expression of UGT1A and UGT2B mRNA in human normal tissues and various cell lines. Drug Metab. Dispos. 36, 1461-1464. doi: 10.1124/dmd.108.021428

Nebert, D. W., and Russell, D. W. (2002). Clinical importance of the cytochromes P450. Lancet 360, 1155-1162. doi: 10.1016/S0140-6736(02)11203-7

Nguyen, N., Bonzo, J. A., Chen, S., Chouinard, S., Kelner, M. J., Hardiman, G., et al. (2008). Disruption of the ugtl locus in mice resembles human Crigler-Najjar type I disease. J. Biol. Chem. 283, 7901-7911. doi: 10.1074/jbc.M709244200

Nishihara, M., Hiura, Y., Kawaguchi, N., Takahashi, J., and Asahi, S. (2013). UDPglucuronosyltransferase 2B15 (UGT2B15) is the major enzyme responsible for sipoglitazar glucuronidation in humans: Retrospective identification of the UGT isoform by in vitro analysis and the effect of UGT2B15* 2 mutation. Drug Metab. Pharmacokinet. 28, 475-484. doi: 10.2133/dmpk.DMPK-13-RG-004

Offen, W., Martinez-Fleites, C., Yang, M., Kiat-Lim, E., Davis, B. G., Tarling, C. A., et al. (2006). Structure of a flavonoid glucosyltransferase reveals the basis for plant natural product modification. EMBO J. 25, 1396-1405. doi: 10.1038/sj.emboj.7600970

Operaña, T. N., and Tukey, R. H. (2007). Oligomerization of the UDPglucuronosyltransferase 1A proteins: homo- and heterodimerization analysis by fluorescence resonance energy transfer and co-immunoprecipitation. J. Biol. Chem. 282, 4821-4829. doi: 10.1074/jbc.M609417200

Patana, A. S., Kurkela, M., Goldman, A., and Finel, M. (2007). The human UDPglucuronosyltransferase: identification of key residues within the nucleotidesugar binding site. Mol. Pharmacol. 72, 604-611. doi: 10.1124/mol.107.036871

Peer, C. J., Sissung, T. M., Kim, A., Jain, L., Woo, S., Gardner, E. R., et al. (2012). Sorafenib is an inhibitor of UGT1A1 but is metabolized by UGT1A9: implications of genetic variants on pharmacokinetics and hyperbilirubinemia. Clin. Cancer Res. 18, 2099-2107. doi: 10.1158/1078-0432.CCR-11-2484

Peters, W. H., Jansen, P. L., and Nauta, H. (1984). The molecular weights of UDP-glucuronyltransferase determined with radiation-inactivation analysis. A molecular model of bilirubin UDP-glucuronyltransferase. J. Biol. Chem. 259, 11701-11705.

Rouleau, M., Roberge, J., Bellemare, J., and Guillemette, C. (2014). Dual roles for splice variants of the glucuronidation pathway as regulators of cellular metabolism. Mol. Pharmacol. 85, 29-36. doi: 10.1124/mol.113.089227

Rowland, A., Elliot, D. J., Williams, J. A., Mackenzie, P. I., Dickinson, R. G., and Miners, J. O. (2006). In vitro characterization of lamotrigine N2glucuronidation and the lamotrigine-valproic acid interaction. Drug Metab. Dispos. 34, 1055-1062.

Sato, Y., Nagata, M., Tetsuka, K., Tamura, K., Miyashita, A., Kawamura, A., et al. (2014). Optimized methods for targeted peptide-based quantification of human uridine $5^{\prime}$-diphosphate-glucuronosyltransferases in biological specimens using liquid chromatography-tandem mass spectrometry. Drug Metab. Dispos. 42, 885-889. doi: 10.1124/dmd.113.056291

Satoh, T., and Hosokawa, M. (1998). The mammalian carboxylesterases: from molecules to functions. Annu. Rev. Pharmacol. Toxicol. 38, 257-288. doi: 10.1146/annurev.pharmtox.38.1.257

Schirris, T. J., Ritschel, T., Bilos, A., Smeitink, J. A., and Russel, F. G. (2015). Statin lactonization by uridine $5^{\prime}$-diphospho-glucuronosyltransferases (UGTs). Mol. Pharm. 12, 4048-4055. doi: 10.1021/acs.molpharmaceut. 5 b00474

Shao, H., He, X., Achnine, L., Blount, J. W., Dixon, R. A., and Wang, X. (2005). Crystal structures of a multifunctional triterpene/flavonoid glycosyltransferase from Medicago truncatula. Plant Cell 17, 3141-3154. doi: $10.1105 /$ tpc. 105.035055

Shi, W. W., Jiang, Y. L., Zhu, F., Yang, Y. H., Shao, Q. Y., Yang, H. B., et al. (2014). Structure of a novel O-linked N-acetyl-D-glucosamine (O-GlcNAc) transferase, GtfA, reveals insights into the glycosylation of pneumococcal serine-rich repeat adhesins. J. Biol. Chem. 289, 20898-20907. doi: 10.1074/jbc.M114. 581934

Smith, P. A., Sorich, M. J., McKinnon, R. A., and Miners, J. O. (2003). Pharmacophore and quantitative structure-activity relationship modeling: complementary approaches for the rationalization and prediction of UDPglucuronosyltransferase 1A4 substrate selectivity. J. Med. Chem. 46, 1617-1626. doi: $10.1021 /$ jm020397c

Sneitz, N., Court, M. H., Zhang, X., Laajanen, K., Yee, K. K., Dalton, P., et al. (2009). Human UDP-glucuronosyltransferase UGT2A2: cDNA construction, expression, and functional characterization in comparison with UGT2A1 and UGT2A3. Pharmacogenet. Genomics 19, 923-934. doi: 10.1097/FPC.0b013e3283330767

Song, J. H., Cui, L., An, L. B., Li, W. T., Fang, Z. Z., Zhang, Y. Y., et al. (2015). Inhibition of UDP-glucuronosyltransferases (UGTs) activity by constituents of Schisandra chinensis. Phytother. Res. 29, 1658-1664. doi: 10.1002/ptr.5395

Strassburg, C. P., Oldhafer, K., Manns, M. P., and Tukey, R. H. (1997). Differential expression of the UGT1A locus in human liver, biliary, and gastric tissue: identification of UGT1A7 and UGT1A10 transcripts in extrahepatic tissue. Mol. Pharmacol. 52, 212-220.

Sumida, K., Kawana, M., Kouno, E., Itoh, T., Takano, S., Narawa, T., et al. (2013). Importance of UDP-glucuronosyltransferase 1A1 expression in skin and its induction by UVB in neonatal hyperbilirubinemia. Mol. Pharmacol. 84, 679-686. doi: 10.1124/mol.113.088112

Takeda, S., Ishii, Y., Iwanaga, M., Mackenzie, P. I., Nagata, K., Yamazoe, Y., et al. (2005). Modulation of UDP-glucuronosyltransferase function by 
cytochrome P450: evidence for the alteration of UGT2B7-catalyzed glucuronidation of morphine by CYP3A4. Mol. Pharmacol. 67, 665-672. doi: 10.1124/mol.104.007641

Takeda, S., Ishii, Y., Iwanaga, M., Nurrochmad, A., Ito, Y., Mackenzie, P. I., et al. (2009). Interaction of cytochrome P450 3A4 and UDP-glucuronosyltransferase 2B7: evidence for protein-protein association and possible involvement of CYP3A4 J-helix in the interaction. Mol. Pharmacol. 75, 956-964. doi: 10.1124/mol.108.052001

Taura, K. I., Yamada, H., Hagino, Y., Ishii, Y., Mori, M. A., and Oguri, K. (2000). Interaction between cytochrome P450 and other drug-metabolizing enzymes: evidence for an association of CYP1A1 with microsomal epoxide hydrolase and UDP-glucuronosyltransferase. Biochem. Biophys. Res. Commun. 273, 10481052. doi: 10.1006/bbrc.2000.3076

Tourancheau, A., Margaillan, G., Rouleau, M., Gilbert, I., Villeneuve, L., Lévesque, E., et al. (2016). Unravelling the transcriptomic landscape of the major phase II UDP-glucuronosyltransferase drug metabolizing pathway using targeted RNA sequencing. Pharm. J. 16, 60-70. doi: 10.1038/tpj.2015.20

Tripathi, S. P., Prajapati, R., Verma, N., and Sangamwar, A. T. (2016). Predicting substrate selectivity between UGT1A9 and UGT1A10 using molecular modelling and molecular dynamics approach. Mol. Simul. 42, 270-288. doi: 10.1080/08927022.2015.1044451

Tukey, R. H., and Tephly, T. R. (1981). Purification of properties of rabbit liver estrone and p-nitrophenol UDP-glucuronyltransferases. Arch. Biochem. Biophys. 209, 565-578. doi: 10.1016/0003-9861(81)90314-3

Turgeon, D., Carrier, J. S., Chouinard, S., and Bélanger, A. (2003). Glucuronidation activity of the UGT2B17 enzyme toward xenobiotics. Drug Metab. Dispos. 31, 670-676. doi: 10.1124/dmd.31.5.670

Watanabe, Y., Nakajima, M., Ohashi, N., Kume, T., and Yokoi, T. (2003). Glucuronidation of etoposide in human liver microsomes is specifically catalyzed by UDP-glucuronosyltransferase 1A1. Drug Metab. Dispos. 31, 589595. doi: 10.1124/dmd.31.5.589

Widmer, C. C., Pereira, C. P., Gehrig, P., Vallelian, F., Schoedon, G., Buehler, P. W., et al. (2010). Hemoglobin can attenuate hydrogen peroxide-induced oxidative stress by acting as an antioxidative peroxidase. Antioxid. Redox. Signal. 12, 185-198. doi: 10.1089/ars.2009.2826
Williams, J. A., Hyland, R., Jones, B. C., Smith, D. A., Hurst, S., Goosen, T. C., et al. (2004). Drug-drug interactions for UDP-glucuronosyltransferase substrates: a pharmacokinetic explanation for typically observed low exposure (AUCi/AUC) ratios. Drug Metab. Dispos. 32, 1201-1208. doi: 10.1124/dmd.104. 000794

Wu, B., Wang, X., Zhang, S., and Hu, M. (2012). Accurate prediction of glucuronidation of structurally diverse phenolics by human UGT1A9 using combined experimental and in silico approaches. Pharm. Res. 29, 1544-1561. doi: 10.1007/s11095-012-0666-Z

Xiong, Y., Bernardi, D., Bratton, S., Ward, M. D., Battaglia, E., Finel, M., et al. (2006). Phenylalanine 90 and 93 are localized within the phenol binding site of human UDP-glucuronosyltransferase $1 \mathrm{~A} 10$ as determined by photoaffinity labeling, mass spectrometry, and site-directed mutagenesis. Biochemistry 45, 2322-2332. doi: 10.1021/bi0519001

Yao, Z., Liu, Y. Z., Ma, A. L., Wang, S. F., Lu, D., Hu, C. M., et al. (2015). Chiral inhibition of rivaroxaban derivatives towards UDP-glucuronosyltransferase (UGT) isoforms. Chirality 27, 936-943. doi: 10.1002/chir.22505

Yuan, L., Qian, S., Xiao, Y., Sun, H., and Zeng, S. (2015). Homo-and heterodimerization of human UDP-glucuronosyltransferase 2B7 (UGT2B7) wild type and its allelic variants affect zidovudine glucuronidation activity. Biochem. Pharmacol. 95, 58-70. doi: 10.1016/j.bcp.2015.03.002

Zhang, Q., Cao, Y. F., Ran, R. X., Li, R. S., Wu, X., Dong, P. P., et al. (2016). Strong specific inhibition of UDP-glucuronosyltransferase $2 \mathrm{~B} 7$ by atractylenolide I and III. Phytother. Res. 30, 25-30. doi: 10.1002/ptr.5496

Conflict of Interest Statement: The authors declare that the research was conducted in the absence of any commercial or financial relationships that could be construed as a potential conflict of interest.

Copyright (c) 2016 Fujiwara, Yokoi and Nakajima. This is an open-access article distributed under the terms of the Creative Commons Attribution License (CC BY). The use, distribution or reproduction in other forums is permitted, provided the original author(s) or licensor are credited and that the original publication in this journal is cited, in accordance with accepted academic practice. No use, distribution or reproduction is permitted which does not comply with these terms. 